\title{
Adsorption Kinetics of Malachite Green and Methylene Blue from Aqueous Solutions Using Surfactant-modified Organoclays
}

\author{
Haseeb Ullah, ${ }^{1}$ Muhammad Nafees, ${ }^{2}$ Farhat Iqbal, ${ }^{3}$ Muhammad Saifullah Awan, ${ }^{4}$ \\ Afzal Shah ${ }^{1}$ and Amir Waseem ${ }^{1, *}$ \\ ${ }^{1}$ Department of Chemistry, Quaid-i-Azam University, Islamabad-45320, Pakistan \\ ${ }^{2}$ State Key Laboratory of Coordination Chemistry, School of Chemistry and Chemical Engineering, \\ Nanjing University, Nanjing-210093, China \\ ${ }^{3}$ Department of Statistics, University of Balochistan, Quetta-Pakistan \\ ${ }^{4}$ Ibn-i-Sina Institute of Technology, H-11/4, Islamabad, Pakistan \\ * Corresponding author: E-mail: waseemq2000@hotmail.com
}

Received: 14-02-2017

\begin{abstract}
The main objective of this research is to study the adsorption behaviour of malachite green and methylene blue dyes onto the surfactant modified natural clays. The results of SEM, XRD, IR, and thermal analysis confirms the intercalation of organic moiety in to the clay. The adsorption results show that pseudo-first order kinetics best fitted for both the dyes adsorbed on organo-clay. The data also reveals that both dyes are in a good agreement with Langmuir isotherm in both types of modified clays. The value of separation factor, $R_{\mathrm{L}}$, from Langmuir equation and Freundlich constant, $\mathrm{n}$, give an indication of favourable adsorption. The maximum adsorption capacity $\mathrm{q}_{\mathrm{m}}$ based on Langmuir model was found to be $294-303 \mathrm{mg} / \mathrm{g}$ at $25^{\circ} \mathrm{C}$, is in good agreement with the experimental values.
\end{abstract}

Keywords: Environmental remediation, montmorillonite, dyes, cationic surfactants, isotherm models.

\section{Introduction:}

Ecological issues have turned into a worldwide concern in the light of their effect on public health. ${ }^{1,2}$ Almost $25 \%$ of the sicknesses confronting people today is because of their long-term exposure to environmental pollutants. ${ }^{3}$ Dye-bearing effluents are one of the most significant contributors from the textile field and such effluents have a wide detrimental impact on the human health. ${ }^{4,5}$ It has been estimated that annually $7 \times 10^{5}$ metric ton of different commercial dyes and pigments are being produced globally, and of which 5-10\% are being lost and discharged into the wastewater in the form of industrial effluents. ${ }^{6,7}$ Among them azo dyes are the one most widely used and accounts $65-70 \%$ of the total dyes produced. ${ }^{8}$ A great deal of dyes exists and exhibit structural variations and can be classified in several ways. These can be classified due to their structural similarity or application to the fiber type. ${ }^{9,10}$
Dyes, such as malachite green (MG) and methylene blue (MB) have been used extensively as model dyes for adsorption studies onto various low cost adsorbents. ${ }^{8}$ In addition, MG is largely being utilized as a food colouring agent, food additive, and a therapeutic disinfectant and anthelminthic as well as a dye in a vast majority of industries, ${ }^{11}$ On the other hand, MB is generally being utilized as a colouring agent in the biomedical field such as in microbiology, surgery, and diagnostics. ${ }^{12}$ Beside their greater use, they have now turned into an exceedingly questionable compounds because of the risks it (MG) postures to the consumers of treated fish including its effects on the immune and reproductive system, ${ }^{13,14}$ similarly, intense exposure to $\mathrm{MB}$ can bring about numerous health risks such as fast pulse, skin disease, jaundice, and tetraplegia and tissue necrosis. ${ }^{6}$

In response to concerns regarding the health risks associated with the utilization of dyes, adsorption is prob- 
ably the most adaptable and versatile approach for the expulsion of dyes from aqueous solutions..$^{15}$ Sometimes, it is conceivable to recoup the adsorbed dye through desorption and also to reuse the huge amount of water utilized by textile sector. Adsorption has been observed to be one of the very most effective physicochemical techniques, better than numerous different approaches for water reuse in terms of the simplicity of operation. The design of adsorption system play a crucial role in order to generate high quality treated effluent. ${ }^{16,17}$ Activated carbon has been generally utilized for this reason in view of its high adsorption capacity; however, its high cost tends to limit its use. In the past few decades, much research has been focused on the development of adsorbents from natural sources, for example, naturally occurring clays, zeolites, and other cheap and accessible solid materials to remove dyes from wastewater. ${ }^{18}$ Clay minerals are appropriate for adsorption process because of their specific surface area and nanometer-scale size. ${ }^{19}$ Recent progress in the synthesis of nanostructured materials offers a broader spectrum to change surface properties of naturally occurring clays in order to increase their adsorption properties. The organoclays (OCs) are set up by introducing cationic surfactant molecules (e.g. hexadecyltrimethylammonium, HDTMA, trimethylammonium TMA etc) into the interlamellar space of a clay (e.g. smectite) through ion exchange which consequently change the surface properties of natural clay from hydrophilic to hydrophobic. ${ }^{20}$ The OCs have long been used for the adsorption of a range of organic compounds from water and wastewater. ${ }^{18,21-23}$

Adsorption process is a surface phenomenon, where substance of interest is concentrated on the surface of solid adsorbent material. Liquid and gaseous substances can be adsorbed in suitable adsorbent and is widely used in isolation and purification processes in the chemical industries including biotechnology and environmental technology. ${ }^{24-26}$ Adsorption is very reasonably superior technique because of simplicity of design availability, ability to treat dyes more concentrated from other techniques. ${ }^{27,28}$ Being a dynamic process, the rate of adsorption in adsorption equilibrium is controlled by mass transfer processes. The amount of adsorbate (analyte) adsorbed per unit mass is determined through equilibrium, where data is represented in the form of adsorption isotherms. ${ }^{24}$ Literature review shows the number of models which govern adsorption equilibrium, out of them the Langmuir and the Freundlich isotherm models are the most commonly used, others include modified Freundlich, Sips, Redlich-Peterson, Dubnin-Radushkevich constants, Tempkin constants etc. ${ }^{24,29}$ Several steps can be used to study the controlling mechanism of adsorption process such as chemical reaction, diffusion control, and mass transfer; kinetic models are used to the experimental data from the adsorption process. ${ }^{28}$ The kinetic parameters are useful for the prediction of adsorption rate, and gives valuable information for designing and modelling the adsorption processes.
Various structural and non-structural models have been described in the literature with variable degree of success. ${ }^{24,30}$ Some of them are: pseudo first and second-order rate expressions; which are most often used, other includes intraparticle diffusion model, Bangham's equation etc. ${ }^{24,30,31}$

The aim of this study was to examine the adsorption capability of natural clay (Pakistan based montmorillonite) for removal of malachite green (MG) and methylene blue (MB) as a model dyes from aqueous solutions. The peculiar montmorillonite was gotten from Khyber Pakhtunkhwa region of Pakistan, and emended with a cationic surfactant, Hexadecyl trimethylammonium bromide (HDTMA) and Hexadecylpyridinium chloride (HDPy), in order to assess the changes in the clays and its adsorption capacity. The structures of natural and organoclay were assessed by utilizing, Powdered X-ray diffraction (XRD), X-ray Fluorescence microscopy (XRF) Fourier Transform infrared (FT-IR) spectroscopy, Scanning electron microscopy (SEM) and Ther-mogravimetric analysis (TGA). The impacts of various parameters, for example, $\mathrm{pH}$, contact time, dye concentration and adsorbent dosage were also studied. The adsorption systems of dyes (MG \& MB) onto organoclay were assessed in terms of adsorption isotherms which were portrayed by utilizing Langmuir and Freundlich isotherm models.

\section{Materials and Methods}

\section{1. Materials}

Both quaternary ammonium salts, hexadecylpyridinium chloride (HDPy) and hexadecyltrimethylammonium bromide (HDTMA) were purchased from SigmaAldrich and used without any purification. The cationic dyes methylene blue (MB) $\mathrm{C}_{16} \mathrm{H}_{18} \mathrm{ClN}_{3} \mathrm{~S} \cdot 3 \mathrm{H}_{2} \mathrm{O}(98 \%)$ and malachite green (MG) $\mathrm{C}_{23} \mathrm{H}_{25} \mathrm{ClN}_{2}(96 \%)$ were used as the adsorbate in this study and obtained from Sigma-Aldrich. All the chemicals used were of analytical reagents grade being purchased from Merck and were used without further purification.

\section{2. Preparation of Organoclays}

The organoclays were synthesized according to the general procedure described as under. The clay impurities were removed by sedimentation method, followed by oven drying at $110{ }^{\circ} \mathrm{C}$ for $3 \mathrm{~h}$ and pulverized through $200 \mu \mathrm{m}$ sieve. Briefly, thirty millilitres of the quaternary ammonium salt solution (1:1 CEC) was placed in a beaker and $1 \mathrm{~g}$ of pre-dried clay was added into it. The mixture was stirred with the magnetic stirrers for about $16 \mathrm{~h}$ at room temperature, followed by centrifugation and washing several times with deionized water until no halides ions were detected from the supernatant. The modified clays were oven dried 
at $60{ }^{\circ} \mathrm{C}$ for 5 hours, ground to $74 \mu \mathrm{m}$ sizes and finally stored in a desiccator for later use.

\section{3. Characterization Methods}

Characteristics of the adsorbent materials are imperative in evaluating the mechanism of adsorbate binding onto the surface of the adsorbent. The chemical analysis of the natural clay was determined using X-ray fluorescence (XRF) spectrometer (Phillips PW 1404 Xray spectrometer). The basal spacing patterns of the clay mineral were analysed through X-ray diffraction (XRD). The data are recorded on a Philips PANanalytical X'pert PRO diffractometer using $\mathrm{CuK} \alpha$ radiation $(\lambda=1.540598$ $\AA$ A). The diffractometer was operated at accelerating voltage of $40 \mathrm{kV}$ and the emission current of $30 \mathrm{~mA}$, and scan range $(2 \theta=$ from 2 to 10$)$ at a step size of $0.015^{\circ}$. The Fourier Transform Infrared (FT-IR) spectra of natural and organoclay were recorded to examine the surface functional group using Nicolet Nexus 870 FT-IR spectrometer in the region $500-4000 \mathrm{~cm}^{-1}$ with resolution of $4 \mathrm{~cm}^{-1}$ and ten interferograms recorded for each sample. An FEI Quanta 450 scanning electron microscope (SEM) was used to define the change in surface morphology of natural and organoclay. The thermogravimetric analyses (TGA) were performed using PerkinElmer Thermogravimetric analyser instrument in an atmosphere of nitrogen $\left(90 \mathrm{~cm}^{3} / \mathrm{min}\right)$ at a heating rate of 10 ${ }^{\circ} \mathrm{C} / \mathrm{min}$ in a temperature range of $25-800{ }^{\circ} \mathrm{C}$. The BET surface area and average pore size of the samples were performed by (Micromeritics, ASAP 2020) System. The cation exchange capacity (CEC) of the clay was measured using a simple $\mathrm{BaCl}_{2}$ method. ${ }^{32}$

\section{4. Adsorption Studies Method}

The adsorption study of dyes on modified MMt was carried out by batch equilibrium experiment of known amount of the adsorbent with $50 \mathrm{ml}$ of aqueous dye solutions of known concentration in a series of $100 \mathrm{ml}$ stoppered flasks. The solution mixtures were kept under isothermal conditions in a shaking water bath at $150 \mathrm{rpm}$ at the desired temperature. At predefined time, the solution mixtures were removed from the shaker, and centrifuged. The residual dye concentration in the reaction mixture were analyzed by UV/Vis spectrophotometer (Shimadzu UV1700 Japan) using calibration curve. The effect of various experimental factors such as $\mathrm{pH}$, adsorbent dose, initial dye concentration and contact time were investigated employing the univariate approach. After each adsorption experiment, the suspensions were centrifuged, filtered through $0.45 \mu \mathrm{m}$ of nitrocellulose membrane (Sartorius Stedim Biotech. $\mathrm{GmbH}$ ), to remove the solid organoclays particles and the supernatant were subsequently analysed by spectrophotometer for the residual concentration of the MB and MG. The sorption efficiency
(S\%) and adsorption capacity at equilibrium $\left(q_{\mathrm{e}}\right)$ were calculated by using the following equations:

$$
\begin{aligned}
& \text { Sorption Efficiency }(S \%)=\frac{\left(C_{0}-C_{\mathrm{e}}\right)}{C_{\mathrm{e}}} \times 100 \\
& q_{\mathrm{e}}=\frac{\left(C_{\mathrm{o}}-C_{\mathrm{e}}\right) \times V}{m}
\end{aligned}
$$

Where $C_{\hat{\imath}}(\mathrm{mg} / \mathrm{L})$ represents is the initial dye concentration, $C_{\mathrm{e}}(\mathrm{mg} / \mathrm{L})$ is the equilibrium concentration of dye, $\mathrm{V}$ is the volume of solution ( $\mathrm{L})$, and $\mathrm{m}$ is the mass of adsorbent (g).

\section{Results and Discussion}

\section{1. Material Characterization}

\section{1. 1. XRF, CEC \& BET}

The host clay utilized was a montmorillonite (MMt) (Smectite clay) from Khyber-Pakhtunkhwa (KPK) region of Pakistan. There are many MMt deposits available in Pakistan, but most of them including KPK are $\mathrm{Ca}$ bentonites. The chemical compositions of MMt was found to be (weight \%) $57.38 \pm 0.11 \% \mathrm{SiO}_{2}, 2.33 \pm 0.05 \% \mathrm{MgO}$, $15.20 \pm 0.10 \% \mathrm{Al}_{2} \mathrm{O}_{3}, 1.10 \pm 0.03 \% \mathrm{~K}_{2} \mathrm{O}, 4.07 \pm 0.06 \%$ $\mathrm{CaO}, 2.72 \pm 0.03 \% \mathrm{Na}_{2} \mathrm{O}, 0.1 \pm 0.02 \% \mathrm{SO}_{3}, 6.49 \pm 0.07 \%$ $\left(\mathrm{FeO}+\mathrm{Fe}_{2} \mathrm{O}_{3}\right)$ as determined by XRF. Results of XRF declare that predominant exchangeable cation was calcium along with sodium and potassium. The cation exchange capacity (CEC) of MMt clay was found to be 68.3 $\mathrm{meq} / 100 \mathrm{~g}$ and a BET surface area of $58 \mathrm{~m}^{2} / \mathrm{g}$.

\section{1. 2. FT-IR}

To understand the presence of functional groups onto the surfaces of the adsorbent with and without modification, the FT-IR spectral analysis was performed within the range of $400-4000 \mathrm{~cm}^{-1}$. The FT-IR spectra of natural clay, HDP-clay and HDTMA-clay are shown in Figure 2. The IR region between $3700-3000 \mathrm{~cm}^{-1}$ shows the region of $\mathrm{OH}$ stretching and is observed by two key bands and is observed in almost all the natural hydrous silicate (Fig. 1).

Different stretching vibrations of $\mathrm{OH}$ are present in this region. A peak at $3621 \mathrm{~cm}^{-1}$ for MMt is assigned to $\mathrm{OH}$ stretching vibrations for the structural hydroxyl group attached to the octahedral magnesium and the tetrahedral silicon. The bands at 3404 , and $3243 \mathrm{~cm}^{-1}$ can be ascribed to water molecules, within the interlayer of the clay which are hydrogen bonded adsorbed. The bands between $3500-3000 \mathrm{~cm}^{-1}$ are relatively dependent on the concentration of surfactant loaded on clay and becomes broad upon loading. The conformational changes of the surfactant loading on clay can be monitored through the sensitive $\mathrm{CH}$ stretching bands. The $\mathrm{CH}$ stretching region (2700 and $2900 \mathrm{~cm}^{-1}$ ) for the clay loaded with surfactant mole- 
cule shows asymmetric $v_{\mathrm{as}}\left(\mathrm{CH}_{2}\right)$ and symmetric $v_{\mathrm{s}}\left(\mathrm{CH}_{2}\right)$ stretching modes of $2920 \mathrm{~cm}^{-1}$ and $2853 \mathrm{~cm}^{-1}$. The region between $1700-1600 \mathrm{~cm}^{-1}$ shows the $\mathrm{HOH}$ bending of adsorbed water molecules in both clay and organoclays (Fig. 2. peak observed at $1641 \mathrm{~cm}^{-1}$ ). The strong band between $1100-900 \mathrm{~cm}^{-1}$ for natural clay and organoclays were assign to the $\mathrm{Si}-\mathrm{O}-\mathrm{Si}$ and $\mathrm{Si}-\mathrm{O}-\mathrm{Al}$ stretching. The peak between $910-800 \mathrm{~cm}^{-1}$ corresponds for the $\mathrm{OH}$ deformation linked to the $\mathrm{Mg}$ and $\mathrm{Al}$. The peaks between 800-600 were assigned to the $\mathrm{Si}-\mathrm{O}$ quartz vibrations.

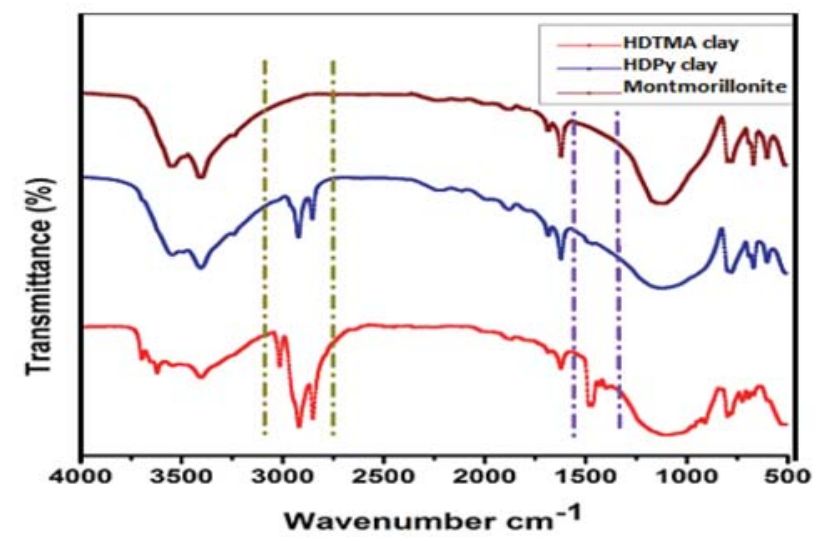

Figure 1. FT-IR spectra of (a) pure clay, (b) HDP-clay, (c) HDTMA-clay

\section{1. 3. XRD}

The potential arrangements of intercalated organic molecules (surfactants) were proposed according to the obtained basal spacing of organoclays and the size of organic cations. ${ }^{15,29,33-35}$ In the current work, the unmodified MMt has a d-spacing of $1.23 \mathrm{~nm}$, which expanded when the intercalated ions were exchanged with surfactants

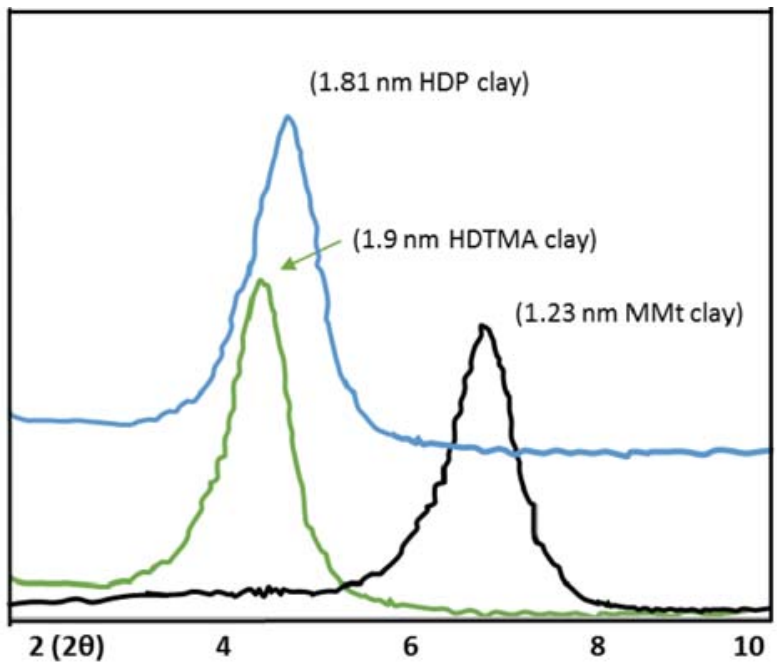

Figure 2. Powder XRD patterns of MMt modified and unmodified clay
(HDTMA or HDP). Upon increasing the HDTMA and HDP loading, the peak at $1.23 \mathrm{~nm}$ disappears due to the increase in interlayer basal spacing and new peaks appeared at 1.81 and $1.90 \mathrm{~nm}$ respectively (Fig. 2). The observed interlayer spacing of MMt and organoclays is used to observe the structural configuration of modified molecule, in the present study lateral-monolayer arrangement was observed with CEC of $1: 1{ }^{20,33,36,37}$

\section{1. 4 SEM}

The resulted SEM photomicrographs of natural clay and organoclays are shown in Figure 4. It is observed that (Fig. 3a), that natural clay has agglomerated structure with
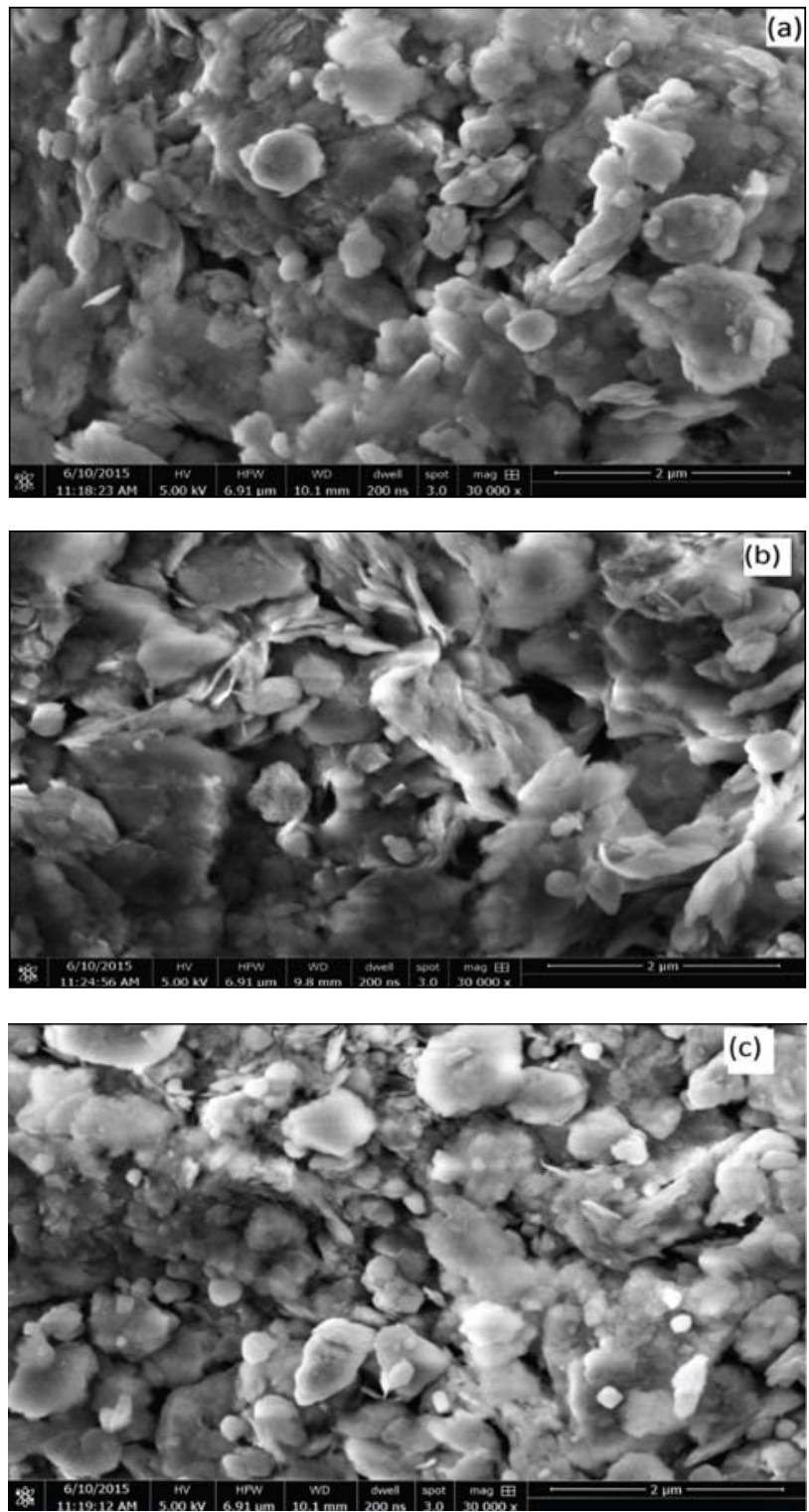

Figure 3. SEM micrograph of (a) pure clay, (b) HDP-clay, (c) HDTMA-clay 
small particle size, smooth and micro-porous surface with fluffy appearance due to the closely packed flakes. The BET surface area of unmodified MMt clay was found to be $58 \mathrm{~m}^{2} / \mathrm{g}$, whereas the modified MMt clay shows the decrease of surface area to $18.5 \mathrm{~m}^{2} / \mathrm{g} \& 16.5 \mathrm{~m}^{2} / \mathrm{g}$ for HDTMA and HDPy surfactant respectively. These results are attributed to the fact that the most of the exchange sites of MMt clay is occupied by organic surfactants molecules with large molecular size and the inaccessibility of the internal surface to nitrogen gas. ${ }^{38}$ However, larger average pore size $(12.2 \mathrm{~nm})$ was observed in modified clay than the precursor clay $(5.2 \mathrm{~nm})$. After the modification of clay with HDMA and HDPy surfactant, the surface morphology slightly changed from foliated structure to non-agglomerated and crumpled structure containing heterogeneous pores with large particles as depicted in Figure 3. MMt have massive and curved plates (Fig. 3a) generally as a heterogeneous surface morphology. ${ }^{33}$ However, the clay modified with organic surfactants shows significant changes in the morphology. Compared with the morphology of the $\mathrm{MMt}$, there are many small and aggregated particles and the plates become relatively flat in while the introduction of organic moiety leads to large particles and coarse porous surface, which may be due to the penetration of organic molecules into the galleries of MMt, resulting in an increase in the adsorption capacity of modified clay. ${ }^{37}$

\section{1. 5. TGA}

Thermogravimetric analysis has been performed to study the arrangement and packing of surfactant molecules within the organoclays and the thermal decomposition behaviour of the organoclay. Thermogravimetric analysis curve for the natural clay and organoclays are shown in Figure 4. TGA pattern of the unmodified natural clay reveals that mass loss occurs mainly at two stages; a) the initial mass loss due to desorption of water occurs at
$30-120{ }^{\circ} \mathrm{C}$ temperature range; b) the second mass loss due to the loss of structural hydroxyl group occurs at 400-540 ${ }^{\circ} \mathrm{C}$ and $580-690{ }^{\circ} \mathrm{C}$ temperature range respectively. ${ }^{39}$ While there are three stages of mass loss with the increase in temperature are occurred for the HDTMA and HDPy modified clay. The first weight loss corresponds to the dehydration of water from organoclays that occur at 30 ${ }^{\circ} \mathrm{C}-180{ }^{\circ} \mathrm{C}$, the weight loss in both the organoclays are lower than the unmodified clay because in organoclays the surfactant molecules replaced some of the water molecules present in clay structure. The second mass loss that is only present in both organoclays is attributed to the removal of surfactant molecules from the organoclays that occurs at $220{ }^{\circ} \mathrm{C}-350{ }^{\circ} \mathrm{C}$ temperature range. This is consistent with the previously reported studies. ${ }^{34,40}$ This corresponds to 7 to $8 \%$ mass loss for both clays, which indicates the surfactant loading to the clays is not very efficient. The last stage shows that besides degradation of Al, Si-polyoxy cations, dehydroxylation of structural hydroxyl unit in clay in the octahedral layer of montmorillonite also takes place. ${ }^{39,40}$

\section{2. Adsorption Optimization Experiments}

Effect of various parameters i.e, the effect of $\mathrm{pH}$, time, adsorbate, and adsorbent concentrations respectively were investigated in univariate design at room temperature $\left(25^{\circ} \mathrm{C}\right)$.

\section{2. 1. Effect of $\mathrm{pH}$}

To investigate the impact of $\mathrm{pH}$ on the adsorption capacity of HDTMA- and HDPy-organoclays for the MG and $\mathrm{MB}$, adsorption tests were performed with an initial dye concentration of $150 \mathrm{mg} / \mathrm{L}$ and organoclay concentration was $0.1 \mathrm{~g}$ and contact time of 30 minutes by varying the $\mathrm{pH}$ of solutions over a range of 3-10. It is clear from the Figure 5 that increasing $\mathrm{pH}$ of a solution, the adsorp-

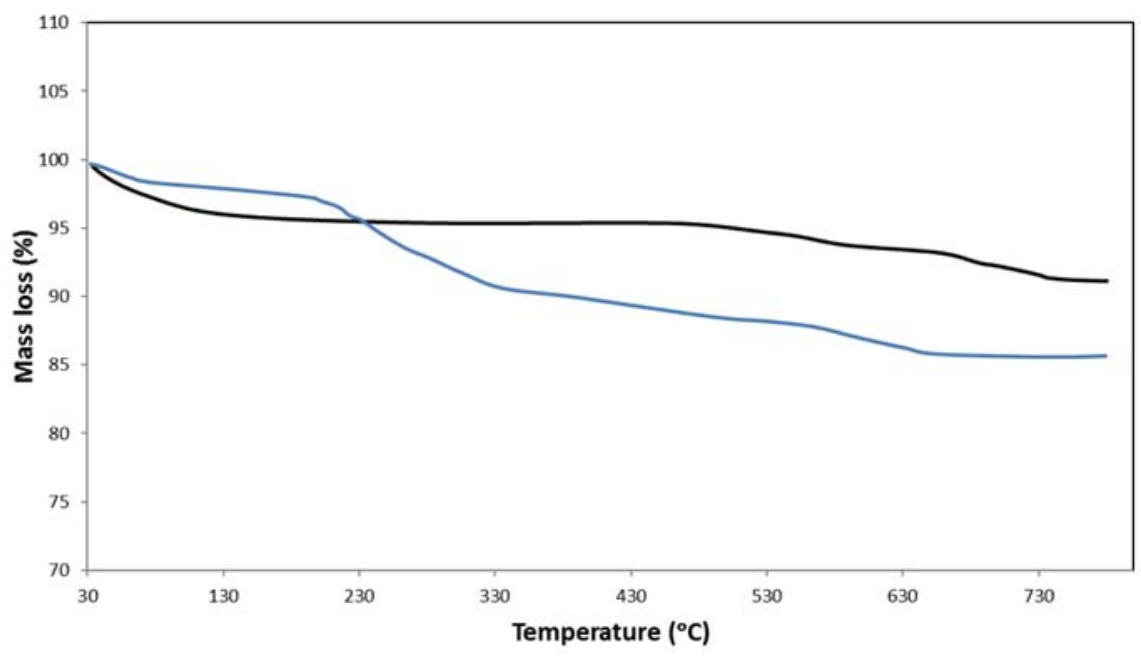

Figure 4. Thermogram of (a) pure clay, (b) organoclay 
tion of cationic dyes also increases. Basically, cationic dyes produces molecular cations $\left(\mathrm{C}^{+}\right)$and reduced ions $\left(\mathrm{CH}^{+}\right)$on dissolution in water ${ }^{31}$ and depends on the water $\mathrm{pH}$. At lower $\mathrm{pH}$, the surface of the adsorbent become protonated results in lower adsorption of the protonated dyes. ${ }^{41}$ Increase in adsorption of dyes with the increase of $\mathrm{pH}$ from 3 to 10 ; is because of the way that the overall positive charge in aqueous solution diminishes and at neutral $\mathrm{pH}$, it shows a balanced surface charge that is required for the adsorption. ${ }^{22,42-44}$ It was observed that both dyes show little increase in sorption after $\mathrm{pH} \mathrm{7,} \mathrm{it} \mathrm{is} \mathrm{therefore} \mathrm{pH} 7$ was selected to investigate the effects of other parameters.
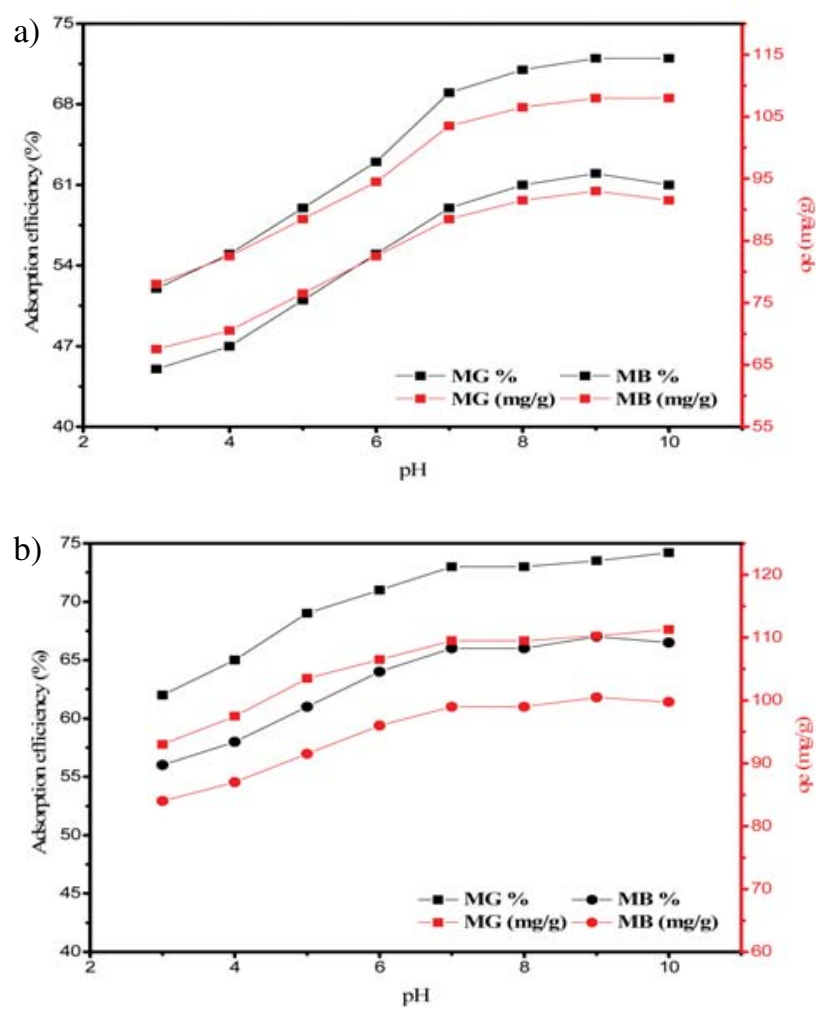

Figure 5. Effect of $\mathrm{pH}$ on the adsorption of $\mathrm{MB}$ and $\mathrm{MG}$ dyes on (a) HDPy-clay (b) HDTMA-clay

\section{2. 2. Effect of Time}

The effect of contact time on the adsorption of MG and MB dyes at various time points onto HDTMA- and HDPy-clays were examined using a fixed adsorbent dose of $0.1 \mathrm{~g}$ and dye concentration was $150 \mathrm{mg} / \mathrm{L}$ at $\mathrm{pH} 7$. As depicted by the Figure 6 that adsorption of both dyes onto the organoclays increases with the increase of contact time, which is consistent with the previous studies. ${ }^{14,29,34}$ At first, the adsorption of dyes occurs through boundary layer adsorption and the adsorptions rates were high because of the accessibility of the higher surface area for the rapid attachment of these dyes to the external exposed surfaces of the organoclays and backs off step by step in the
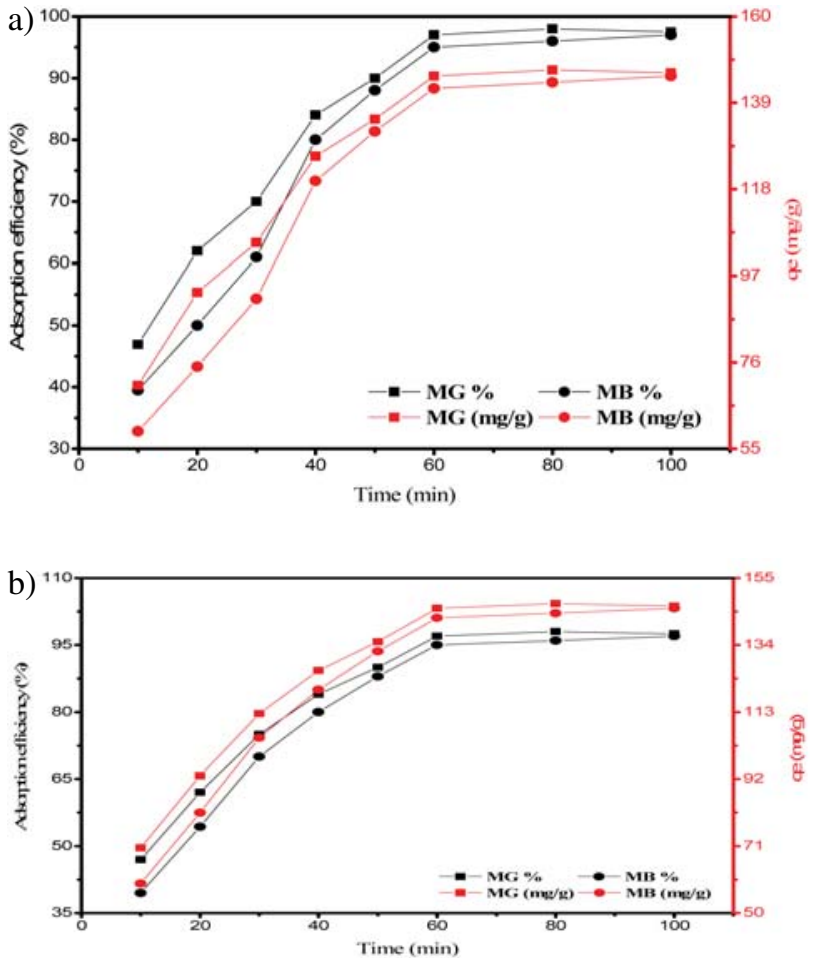

Figure 6. Effect of time on the adsorption of MB and MG dyes on (a) HDPy-clay (b) HDTMA-clay

wake of achieving the equilibrium. After the initial rapid adsorption of dyes, the adsorbent surface gets saturated enough that opposed further adsorption due to the repulsive forces presents between the cationic dye molecules on solid surface and cationic dye molecules present in the bulk phases.

Hence, the adsorption happens because of the diffusion of dyes into the pores of organoclays or might be because of the surface reaction of dyes with the adsorbent clay. ${ }^{45,46}$ There is little increase in dyes adsorption after 60 minutes of equilibrium time, hence 60 minutes selected for further studies.

\section{2. 3. Effect of Initial Dye Concentration}

The initial concentration of adsorbate (dyes) plays important role in adsorption capacity of organoclays. ${ }^{34,47}$ The influence of initial dye concentrations was examined using $0.1 \mathrm{~g}$ of the HDPy and HDTMA-organoclays at $\mathrm{pH} 7$ with equilibrium time of 60 minutes. Figure 7 shows that adsorption of dyes onto organoclays increases with the increase in the concentration of dyes in a solution up to a certain value after which it levelled off. This is because of the fact that an increase in the concentration of dye solution results to produce the high mass gradient pressure between the dye solution and organoclay, this pressure gradient than acts as a driving force for the transfer of dye molecules into the particle surface of the organoclays. ${ }^{4-50}$ The results also indicate that percent removal and adsorption capacity of 
dye onto the organoclay shows opposite trends by varying the concentration of dye solution. Several researchers also found the same adsorption results as function of $\mathrm{MB}$ and MG dye concentration. ${ }^{28,34,45,47,51}$ The inverse patterns for the adsorption capacity and percent removal can be clarified with the way that: there are fixed number of binding sites on the organoclay surface. At the point when the dyes are available in little concentration, the adsorption will be fast and the percent removal of dyes will be high because of the higher number of accessible sites on the surface of organoclays. The quantity of accessible sites for adsorption is higher at lower dyes concentration and deceased with the increase in the concentration of dyes because of the saturation of adsorbed dye molecule. The dye molecules at high concentration compete with each other for the fixed number of binding sites, thus, some of the dye molecules did not get adsorbed and remains in solution, causing lower percent removal of dyes. ${ }^{37,49,52}$

\section{2. 4. Effect of Adsorbent Dose}

The effects of organoclay concentration on the removal of dyes from aqueous solutions were investigated
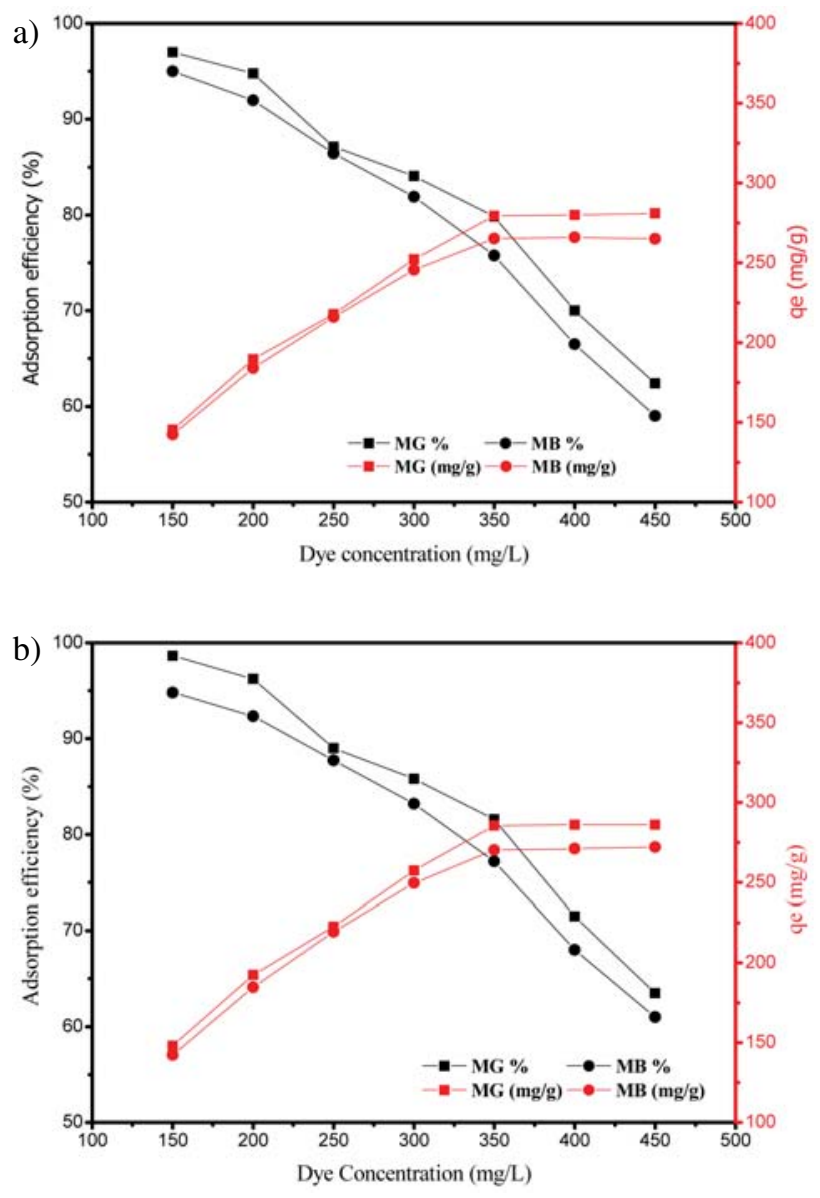

Figure 7. Effect of initial dye concentrations on the adsorption of MB and MG dyes on (a) HDP-clay (b) HDTMA-clay. by using different concentrations of organoclays in the range of $0.1-0.3$ grams and initial dye concentration of $150 \mathrm{mg} \mathrm{L}^{-1}$ at $\mathrm{pH} 7.0$ and equilibrium time of 60 minutes. The results indicate (Fig. 8) that the adsorption efficiency (\%) increases with the increase of adsorbent dosage but show opposite trend for the adsorption capacity, i.e., lesser amount of dye is adsorbed per gram of organoclay. Increase in adsorption efficiency is attributed due to the higher surface area of adsorbent and number of available binding sites for adsorption at a high adsorbent dose. ${ }^{42,45}$ While the decrease in adsorption capacity are attributed due to the fact that total number of dye molecules are fixed $\left(\mathrm{C}_{\mathrm{e}}=150 \mathrm{mg} / \mathrm{L}\right)$ against the increasing organoclay dose $(0.1 \mathrm{~g}$ to 0.3$)$, at higher adsorbent dose some of the adsorption site remains uncovered and thus causing the decrease in the adsorption capacity of the adsorbent. ${ }^{34,53-55}$
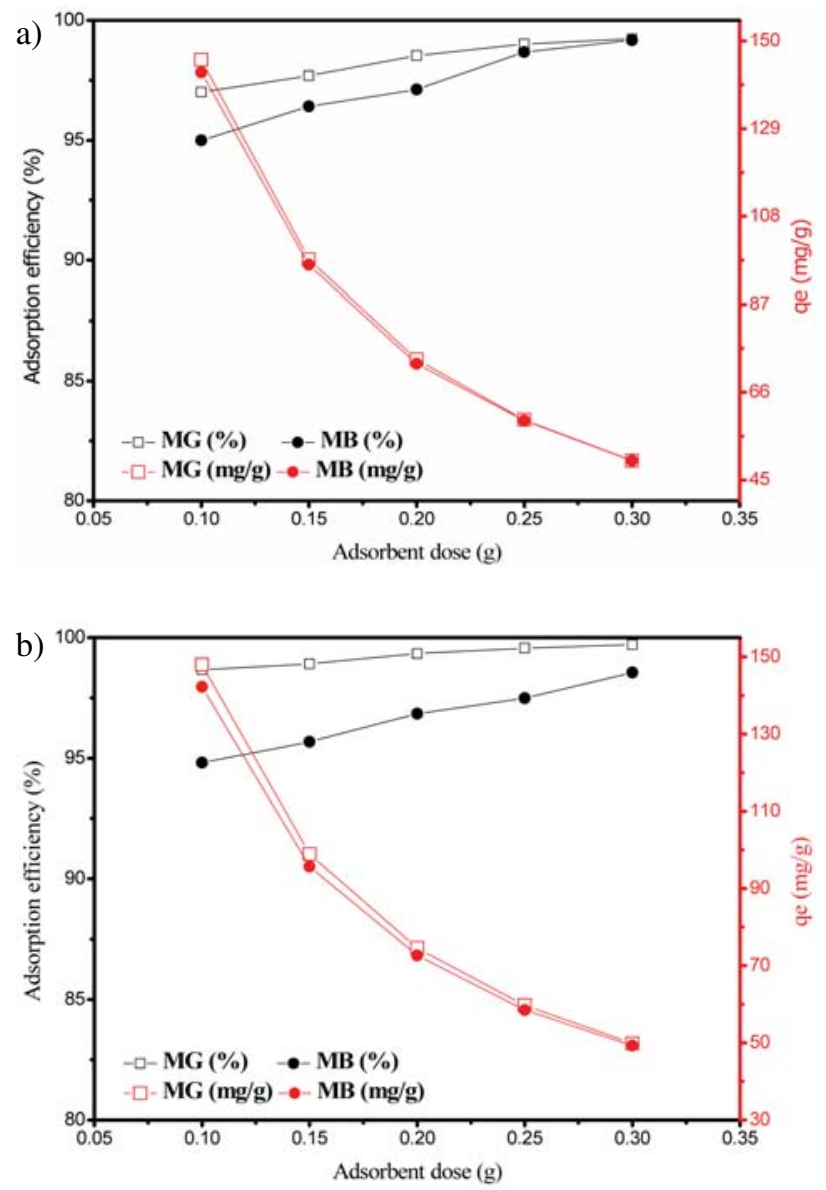

Figure 8. Effect of adsorbent dose on the adsorption of MB and MG dye on (a) HDP-clay (b) HDTMA-clay.

\section{3. Kinetic Study}

The kinetic study is important to understanding the mechanism of the adsorption process. During the process of adsorption of dyes onto the organoclay, the adsorbate 
molecules undergo various stages while moving from the bulk solution to the organoclay surface. Usually to understand the adsorption mechanism, pseudo first-order and pseudo second-order kinetics model were applied. The pseudo first-order model proposed by Lagergren is widely applied for the adsorption of an adsorbate from an aqueous solution. According to this model, the change in rate of the solute uptake with time is directly proportional to the difference in saturation concentration and the solute uptake with time. ${ }^{20,56}$ The linearized integral form of the pseudo first-order model can be expressed as follows:

$$
\log \left(q_{e}-q_{t}\right)=\log q_{e}-\frac{k_{1}}{2.303} t
$$

Where $\mathrm{q}_{\mathrm{e}}(\mathrm{mg} / \mathrm{g})$ and $\mathrm{q}_{\mathrm{t}}(\mathrm{mg} / \mathrm{g})$ are the amounts of dyes adsorbed by organoclay at equilibrium and time $\mathrm{t}$ (min) respectively. $k_{l}\left(\mathrm{~min}^{-1}\right)$ is the equilibrium rate constant of pseudo first-order adsorption. The values of $\mathrm{q}_{\mathrm{e}}$ and adsorption rate constant $\left(k_{l}\right)$ can be calculated from the intercept and the slope of the linear plot of $\log \left(\mathrm{q}_{\mathrm{e}}-\mathrm{q}_{\mathrm{t}}\right)$ verses $t$, respectively. The plot should give a straight line with slope of $-k_{1} / 2.303$ and intercept log qe which allows calculation of adsorption rate constant $k_{1}$ and equilibrium adsorption capacity qe (cal).

The pseudo second-order proposed by Ho and Mckay ${ }^{57}$ based on the assumption that "the rate limiting step are chemisorption involves forces by sharing or exchanging electrons between the adsorbent and the adsorbate" $20,38,56$ and is given as:

$$
\frac{d q_{t}}{d t}=k_{2}\left(q_{e}-q_{t}\right)^{2}
$$

Integrating with the boundary conditions at $\mathrm{t}=0$, $\mathrm{q}_{\mathrm{t}}=0$, and $\mathrm{t}=\mathrm{t}, \mathrm{q}_{\mathrm{t}}=\mathrm{q}_{\mathrm{t}}$ and rearranging, we received.

$$
\frac{t}{q_{t}}=\frac{1}{\left(k_{2} q_{e^{2}}\right)}+\frac{t}{q_{e}}
$$

Where $k_{2}(\mathrm{~g} / \mathrm{mg} \mathrm{min})$ is the rate constant of pseudo second-order adsorption. Ideally the plot of $t / q_{t}$ versus $t$ is a straight line with slope of $1 / \mathrm{q}_{\mathrm{e}}$ and intercept $1 / k_{2} \mathrm{qe}^{2}$. The values of $k_{2}$ and $\mathrm{q}_{\mathrm{e}}$ were calculated from the intercept and slope of the plot respectively. Figure 9, represents the plots of the pseudo-first-order and pseudo-second-order kinetic models of MG and MB onto the organoclays. The optimized condition used for the kinetic studies includes the concentrations of organoclays as 0.1 grams and initial dye concentration of $150 \mathrm{mg} \mathrm{L}^{-1}$ at $\mathrm{pH} 7.0$ at room temperature $\left(25^{\circ} \mathrm{C}\right)$ with varying time. The calculated kinetic parameters of pseudo-first order and pseudo-second order are given in Table 1. The regression coefficients $\left(\mathrm{R}^{2}\right)$ values of pseudo-first order kinetic model are better than those for the pseudo-second order for both types of organoclays. Moreover, the calculated values of equilibrium adsorption capacity are found close to the experimental adsorption capacity onto the organoclays also confirms further the feasibility of the pseudo-first order kinetic model.
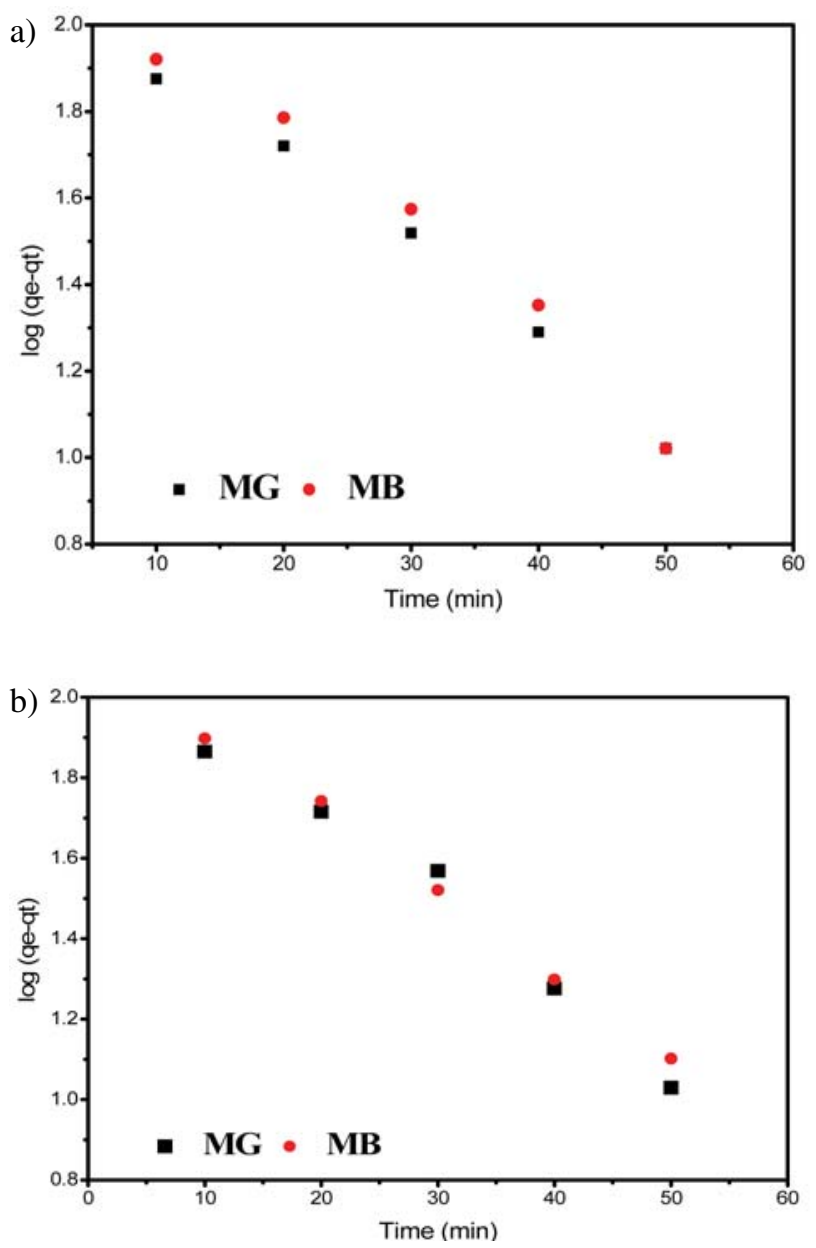

Figure 9. Pseudo-first-order-kinetic model for the adsorption of MB and MG dye on (a) HDP-clay (b) HDTMA-clay.

Table 1. The Pseudo-first and Pseudo-second order kinetic parameters for adsorption of MG and MB on organoclays.

\begin{tabular}{lcccccccc}
\hline \multirow{2}{*}{ Adsorbent } & \multirow{2}{*}{ Dye } & \multicolumn{4}{c}{ Pseudo-first order } & \multicolumn{3}{c}{ Pseudo-second order } \\
& & $\mathbf{q}_{\text {(exp) }}(\mathbf{m g} / \mathbf{g})$ & $\mathbf{q}_{\mathbf{e}(\text { calc) }}(\mathbf{g} / \mathbf{m g})$ & $\boldsymbol{k}_{\mathbf{1}}\left(\mathbf{m i n}^{-\mathbf{1}}\right)$ & $\mathbf{R}^{\mathbf{2}}$ & $\mathbf{q}_{\mathbf{e}(\text { (calc) }}(\mathbf{m g} / \mathbf{g})$ & $\boldsymbol{k}_{\mathbf{2}}(\mathbf{m g} / \mathbf{g})$ & $\mathbf{R}^{\mathbf{2}}$ \\
\hline HDTMA-clay & MG & 147.99 & 145.85 & 0.0532 & 0.9778 & 181.82 & $3.3 \times 10^{-4}$ & 0.9848 \\
HDTMA-clay & MB & 142.22 & 135.67 & 0.0444 & 0.9967 & 175.44 & $2.8 \times 10^{-4}$ & 0.9847 \\
HDP-clay & MG & 145.5 & 133 & 0.0493 & 0.9900 & 178.57 & $3.31 \times 10^{-4}$ & 0.9843 \\
HDP-clay & MB & 142.5 & 158.52 & 0.0514 & 0.9763 & 196.07 & $2.0 \times 10^{-4}$ & 0.9856 \\
\hline
\end{tabular}




\section{4. Adsorption Isotherm Models}

Different isotherm models can be used to analyse the equilibrium adsorption data. ${ }^{25,26,29}$ In this work, the Langmuir and Freundlich isotherm models were used to showing the relationship between the amount of adsorbed MG and MB dyes and their concentration in solution at constant $\mathrm{pH}$ at room temperature. Langmuir isotherm model suggests that the adsorption of adsorbate molecules by the adsorbent materials takes place on a homogenous surface by monolayer without any interaction with adjacent adsorbed molecules. ${ }^{58}$ The linear form of the Langmuir isotherm equation can be represented as follows:

$$
\frac{C_{e}}{q_{e}}=\frac{C_{e}}{q_{m}}+\frac{1}{K_{L} q_{m}}
$$

Where $\mathrm{q}_{\mathrm{m}}(\mathrm{mg} / \mathrm{g})$ represents the maximum adsorption capacity and $K_{\mathrm{L}}(\mathrm{L} / \mathrm{mg})$ is Langmuir adsorption equilibrium constant related to the free energy of adsorption. The adsorption isotherm can be plotted by $\mathrm{C}_{\mathrm{e}} / \mathrm{q}_{\mathrm{e}}$ vs $\mathrm{C}_{\mathrm{e}}$, best fit data should give a straight line, and shows the suitability of the model, where slope of the curve equals to $1 / \mathrm{q}_{\mathrm{m}}$ and intercepts $1 / K_{\mathrm{L}} \mathrm{q}_{\mathrm{m}}$.

Freundlich adsorption isotherm is applicable for a reaction where the multilayer formation occurs due to the heterogeneous adsorption reactions. ${ }^{59}$ The linear form of the Freundlich adsorption isotherm equation can be expressed as:

$$
\ln q e=\ln K_{F}+\frac{1}{n_{F}} \ln C e
$$

Where $\mathrm{q}_{\mathrm{e}}(\mathrm{mg} / \mathrm{g})$ represent the amount of adsorbate adsorbed per unit mass of the adsorbent at equilibrium, $\mathrm{C}_{\mathrm{e}}$ $(\mathrm{mg} / \mathrm{L})$ is the equilibrium adsorbate concentration in solution, $K_{\mathrm{F}}(\mathrm{mg} / \mathrm{g})$ is the Freundlich constants related to the adsorption capacity and $1 / \mathrm{n}_{\mathrm{F}}$ is the heterogeneity factor, the value of " $\mathrm{n}_{\mathrm{F}}$ " is large than 1 indicates the favourable adsorption. These values can be obtained from the linear plot of the $\operatorname{lnq}_{\mathrm{e}} \mathrm{vs} \operatorname{lnC}_{\mathrm{e}}$ where slope $=1 / \mathrm{n}_{\mathrm{F}}$ and intercept $=$ $\ln K_{\mathrm{F}}$.

The results in Table 2, shows that the experimental data fits well for both the isotherm models, however, the regression coefficient $\left(\mathrm{R}^{2}\right)$ values of Langmuir isotherm for both of the dyes are better than that of the Freundlich isotherm, which indicates that adsorption of both dyes takes place as a monolayer on the surface of the modified clay. Further the experimental maximum adsorption capacity is well matched with the $\mathrm{q}_{\mathrm{m}}$ calculated from the Langmuir isotherm model. Based on the Langmuir equation, a dimensionless separation factor, $R_{\mathrm{L}}$ an important parameter indicating the favourability of the adsorption can be calculated using equation given as follows. . $^{74,29,34}$

Table 2. The Langmuir and Freundlich adsorption isotherm parameters.

\begin{tabular}{lccccccccc}
\hline Adsorbent & \multirow{2}{*}{ Dye } & \multirow{2}{*}{ Exp. $\mathbf{q}_{\mathbf{m}}(\mathbf{m g} / \mathbf{g})$} & \multicolumn{3}{c}{ Langmuir } & \multicolumn{3}{c}{ Freundlich } \\
& & & $\mathbf{q}_{\mathbf{m}}(\mathbf{m g} / \mathbf{g})$ & $\boldsymbol{K}_{\mathbf{L}}(\mathbf{L} / \mathbf{m g})$ & $\mathbf{R}^{\mathbf{2}}$ & $\boldsymbol{R}_{\mathbf{L}}$ & $\mathbf{n}$ & $\boldsymbol{K}_{\mathbf{F}}(\mathbf{m g} / \mathbf{g})$ & $\mathbf{R}^{\mathbf{2}}$ \\
\hline HDTMA-clay & MG & 285.5 & 294.12 & 0.22 & 0.9871 & 0.03 & 5.57 & 130.61 & 0.9786 \\
HDTMA-clay & MB & 270.13 & 303.03 & 0.10 & 0.9987 & 0.06 & 3.65 & 84.26 & 0.9825 \\
HDP-clay & MG & 279.4 & 294.12 & 0.145 & 0.9876 & 0.04 & 4.51 & 106.64 & 0.9732 \\
HDP-clay & MB & 265.2 & 294.12 & 0.158 & 0.9974 & 0.04 & 3.93 & 87.67 & 0.989 \\
\hline
\end{tabular}

Table 3. Adsorption efficiency of different adsorbents for MB and MG.

\begin{tabular}{lccc}
\hline Adsorbent & MG (mg/g)/Temp. & MB (mg/g)/Temp. & Reference \\
\hline HDTMA-clay & $285.71(298 \mathrm{~K})$ & $303.03(298 \mathrm{~K})$ & This study \\
HDPy-clay & $277.77(298 \mathrm{~K})$ & $285.71(298 \mathrm{~K})$ & This study \\
Carbon nanotubes & $11.73(328 \mathrm{~K})$ & - & 14 \\
Algerian halloysite heat/acid treated & $192.6(298 \mathrm{~K})$ & - & 60 \\
Diatomite & $23.64(298 \mathrm{~K})$ & - & - \\
Montmorillonite clay & 262.5 & - & 61 \\
Activated carbon loaded with ZnO nanoparticles & 322.58 & - & 63 \\
Halloysite nanotubes & 99.6 & - & 64 \\
Clayey soil & $78.57(303 \mathrm{~K})$ & $106.38(293 \mathrm{~K})$ \\
Chitosan coated bentonite & 435 & 15.6 & 65 \\
Fe $\mathrm{O}_{4} /$ activated montmorillonite nanocomposite & - & $142.86(313 \mathrm{~K})$ \\
kaolinite clay-water interface electrolyte enhanced adsorption & - & $71.12(333 \mathrm{~K})$ \\
Chitosan/bentonite composite & - & $254(298 \mathrm{~K})$ \\
Montmorillonite clay modified with iron oxide & - & $223.19(303 \mathrm{~K})$ \\
Dodecyl sulfobetaine modified montmorillonite clay & - & 66 \\
Acid/Al(OH) modified clay & - & 67 \\
\hline
\end{tabular}


Where $K_{\mathrm{L}}$ is the Langmuir constant and $\mathrm{C}_{\mathrm{o}}$ is the highest initial dye concentration. The value of $R_{L}$ indicates the type of the isotherm to be either favourable $\left(0<R_{L}<\right.$ $1)$, unfavourable $\left(R_{L}>1\right)$, linear $\left(R_{L}=1\right)$ or irreversible $\left(R_{\mathrm{L}}=0\right)$. The results in Table 2 further indicate that the $R_{L}$ values lies between 0 and 1, which shows the favourable Langmuir adsorption process. Comparison of the maximum adsorption capacities and optimized temperature of the removal of MG and MB using proposed organoclays with that of the other similar adsorbent previously reported has been made and presented in Table 3. It shows that most of the recent studies for MG and MB removal possess less Langmuir maximum adsorption capacities comparatively than the low cost proposed organoclays.

\section{Conclusions}

The performance of hexadecyltrimethylammonium/Hexadecylpyridinium-intercalated montmorillonite clay for the removal of malachite green/methylene blue from aqueous solutions has been evaluated in this study. The surface and physical properties of clay and organoclay were evaluate using SEM, XRD, IR, thermal analysis and the results indicated the successful intercalation of these surfactants onto clay. Kinetic characteristic constants of sorption were determined using a pseudofirst/second order equation of Lagergren based solid capacity and pseudo-first order was found suitable. The experimental data were applied to the Langmuir and Freundlich isotherm equations. The results indicate that the experimental data fits well for both the isotherm models, however, the regression coefficient $\left(\mathrm{R}^{2}\right)$ values of Langmuir isotherm for both dyes are better than that of the Freundlich isotherm, which indicates that adsorption of both dyes takes place as a monolayer on the surface of the modified clay. Further the experimental maximum adsorption capacity is well matched with the $\mathrm{q}_{\mathrm{m}}$ calculated from the Langmuir isotherm model.

\section{Acknowledgement}

The authors are grateful to Higher Education Commission, Pakistan for providing financial assistance under NRPU project no. 6172.

\section{References}

1. A. Waseem, J. Arshad, F. Iqbal, A. Sajjad, Z. Mehmood and G. Murtaza, Biomed Research International 2014, vol. 2014, 29 pages. http://dx.doi.org/10.1155/2014/813206.

2. N. Faheem, A. Sajjad, Z. Mehmood, F. Iqbal, Q. Mahmood,

S. Munsif and A. Waseem, Fresenius Environ. Bull. 2015 $24,4555-4566$.
3. Li Zhou, Chao Gao and W. Xu, ACS Appl. Mater. Interfaces 2010, 2, 1483-1491. https://doi.org/10.1021/am100114f

4. R. S. Blackburn, Environ. Sci. Technol. 2004, 38, 49054909. https://doi.org/10.1021/es049972n

5. H. I. Chieng, L. B. Lim and N. Priyantha, Environ. Technol. 2015, 36, 86-97. https://doi.org/10.1080/09593330.2014.938124

6. T. K. Sen, S. Afroze and H. M. Ang, Water, Air, Soil Pollut. 2011, 218, 499-515. https://doi.org/10.1007/s11270-010-0663-y

7. Y. Bulut and H. Karaer, J. Dispersion Sci. Technol. 2014, 36, 61-67. https://doi.org/10.1080/01932691.2014.888004

8. V. K. Gupta and Suhas, J Environ Manage 2009, 90, 231342. https://doi.org/10.1016/j.jenvman.2008.11.017

9. K. Hunger, P. Gregory, P. Miederer, H. Berneth, C. Heid and W. Mennicke: Industrial Dyes, Wiley-VCH Verlag GmbH \& Co. KGaA, 2004, pp. 13-112.

10. K. Hunger, R. Hamprecht, P. Miederer, C. Heid, A. Engel, K. Kunde, W. Mennicke and J. Griffiths: Industrial Dyes, Wiley-VCH Verlag GmbH \& Co. KGaA, 2004, pp. 113-338.

11. Sandra J. Culp and F. A. Beland, International Journal of Toxicolgy 1996, 15, 219-238. https://doi.org/10.3109/10915819609008715

12. S. Afroze, T. K. Sen, M. Ang and H. Nishioka, Desalin Water Treat 2015, 57, 5858-5878. https://doi.org/10.1080/19443994.2015.1004115

13. D. J. Alderman and R. S. Clifton-Hadley, J. Fish Dis. 1993, 16, 297-311. https://doi.org/10.1111/j.1365-2761.1993.tb00864.x

14. M. Rajabi, B. Mirza, K. Mahanpoor, M. Mirjalili, F. Najafi, O. Moradi, H. Sadegh, R. Shahryari-ghoshekandi, M. Asif, I. Tyagi, S. Agarwal and V. K. Gupta, J. Ind. Eng. Chem. 2016, 34, 130-138. https://doi.org/10.1016/j.jiec.2015.11.001

15. B. Mu and A. Wang, J. Environ. Chem. Eng. 2016, 4, 1274 1294. https://doi.org/10.1016/j.jece.2016.01.036

16. P. Wu, T. Wu, W. He, L. Sun, Y. Li and D. Sun, Colloids Surf., A 2013, 436, 726-731. https://doi.org/10.1016/j.colsurfa.2013.08.015

17. S. Elemen, E. P. Akçakoca Kumbasar and S. Yapar, Dyes Pigm. 2012, 95, 102-111. https://doi.org/10.1016/j.dyepig.2012.03.001

18. M. Nafees, A. Waseem and A. R. Khan, The Scientific World Journal, 2013, vol. 2013, 6 pages. http://dx.doi.org/10.1155/2013/681769

19. B. Schampera, R. Solc, S. K. Woche, R. Mikutta, S. Dultz, G. Guggenberger and D. Tunega, Clay Miner. 2015, 50, 353367. https://doi.org/10.1180/claymin.2015.050.3.08

20. Y. Park, G. A. Ayoko, E. Horvath, R. Kurdi, J. Kristof and R. L. Frost, J. Colloid Interface Sci. 2013, 393, 319-34. https://doi.org/10.1016/j.jcis.2012.10.067

21. M. Nafees and A. Waseem, CLEAN 2014, 42, 1500-1508.

22. M. D. Mullassery, N. B. Fernandez and T. S. Anirudhan, Desalin Water Treat 2015, 56, 1929-1939. https://doi.org/10.1080/19443994.2014.958110

23. K. Mukherjee, A. Kedia, K. Jagajjanani Rao, S. Dhir and S. 
Paria, RSC Advances 2015, 5, 30654-30659. https://doi.org/10.1039/C5RA03534A

24. B. Likozar, D. Senica and A. Pavko, AIChE J. 2012, 58, 99 106. https://doi.org/10.1002/aic.12559

25. B. Likozar, D. Senica and A. Pavko, Brazilian Journal of Chemical Engineering 2012, 29, 635-652. https://doi.org/10.1590/S0104-66322012000300020

26. B. Likozar, D. Senica and A. Pavko, Ind. Eng. Chem. Res. 2013, 52, 9247-9258. https://doi.org/10.1021/ie400832p

27. M. T. Yagub, T. K. Sen, S. Afroze and H. M. Ang, Adv. Colloid Interface Sci. 2014, 209, 172-84. https://doi.org/10.1016/j.cis.2014.04.002

28. M. T. Yagub, T. K. Sen and H. Ang, Water, Air, Soil Pollut. 2012, 223, 5267-5282. https://doi.org/10.1007/s11270-012-1277-3

29. A. S. Bhatt, P. L. Sakaria, M. Vasudevan, R. R. Pawar, N. Sudheesh, H. C. Bajaj and H. M. Mody, RSC Advances 2012, 2, 8663. https://doi.org/10.1039/c2ra20347b

30. M. Zabka, M. Minceva and A. E. Rodrigues, Chemical Engineering and Processing: Process Intensification 2006, 45, 150-160. https://doi.org/10.1016/j.cep.2005.07.002

31. D. Kavitha and C. Namasivayam, Bioresour. Technol. 2007, 98, 14-21. https://doi.org/10.1016/j.biortech.2005.12.008

32. William H. Hendershot and M. Duquette, Soil Sci. Soc. Am. J. 1986, 50, 605-608. https://doi.org/10.2136/sssaj1986.03615995005000030013x

33. H. He, R. L. Frost, T. Bostrom, P. Yuan, L. Duong, D. Yang, Y. Xi and J. T. Kloprogge, Appl. Clay Sci. 2006, 31, 262271. https://doi.org/10.1016/j.clay.2005.10.011

34. E. Orucoglu and S. Haciyakupoglu, Journal of Environmental Management 2015, 160, 30-38. https://doi.org/10.1016/j.jenvman.2015.06.005

35. M. Önal and Y. Sarıkaya, Colloids Surf., A 2007, 296, 216221. https://doi.org/10.1016/j.colsurfa.2006.09.046

36. R. Zhu, Q. Chen, H. Liu, F. Ge, L. Zhu, J. Zhu and H. He, Appl. Clay Sci. 2014, 88-89, 33-38.

https://doi.org/10.1016/j.clay.2013.12.010

37. M. Kıranşan, R. D. C. Soltani, A. Hassani, S. Karaca and A. Khataee, J. Taiwan Inst. Chem. Eng. 2014, 45, 2565-2577.

38. L. Wang and A. Wang, J Hazard Mater 2008, 160, 173-180. https://doi.org/10.1016/j.jhazmat.2008.02.104

39. H. Pálková, J. Madejová and P. Komadel, Open Chemistry 2009, 7.

40. Z. Qin, P. Yuan, J. Zhu, H. He, D. Liu and S. Yang, Appl. Clay Sci. 2010, 50, 546-553. https://doi.org/10.1016/j.clay.2010.10.011

41. Z. Sun, C. Li and D. Wu, J. Chem. Technol. Biotechnol. 2010, 85, 845-850. https://doi.org/10.1002/jctb.2377

42. P. Baskaralingam, M. Pulikesi, D. Elango, V. Ramamurthi and S. Sivanesan, J Hazard Mater 2006, 128, 138-144. https://doi.org/10.1016/j.jhazmat.2005.07.049

43. W. Ngah, W. Saime, N. F. M. Ariff, A. Hashim and M. A. K. M. Hanafiah, CLEAN 2010, 38, 394-400.

44. C. Leodopoulos, D. Doulia and K. Gimouhopoulos, Separation \& Purification Reviews 2015, 44, 74-107. https://doi.org/10.1080/15422119.2013.823622

45. B. Nandi, A. Goswami and M. Purkait, J Hazard Mater 2009, 161, 387-395.

https://doi.org/10.1016/j.jhazmat.2008.03.110

46. V. S. Mane and P. V. Babu, Desalination 2011, 273, 321329. https://doi.org/10.1016/j.desal.2011.01.049

47. A. Gürses, Ç. Doğar, M. Yalçın, M. Açıkyıldız, R. Bayrak and S. Karaca, J Hazard Mater 2006, 131, 217-228.

https://doi.org/10.1016/j.jhazmat.2005.09.036

48. B. Karagozoglu, M. Tasdemir, E. Demirbas and M. Kobya, $J$ Hazard Mater 2007, 147, 297-306.

https://doi.org/10.1016/j.jhazmat.2007.01.003

49. M. Auta and B. Hameed, Chem. Eng. J. (Lausanne) 2012, 198, 219-227. https://doi.org/10.1016/j.cej.2012.05.075

50. M. Doğan, M. Alkan, Ö. Demirbas,, Y. Özdemir and C. Özmetin, Chem. Eng. J. (Lausanne) 2006, 124, 89-101. https://doi.org/10.1016/j.cej.2006.08.016

51. Y. Safa and H. N. Bhatti, Desalination 2011, 272, 313-322. https://doi.org/10.1016/j.desal.2011.01.040

52. M. Auta and B. Hameed, J. Ind. Eng. Chem. 2013, 19, 11531161. https://doi.org/10.1016/j.jiec.2012.12.012

53. M. S. U. Rehman, M. Munir, M. Ashfaq, N. Rashid, M. F. Nazar, M. Danish and J.-I. Han, Chem. Eng. J. (Lausanne) 2013, 228, 54-62. https://doi.org/10.1016/j.cej.2013.04.094

54. W.-T. Tsai, H.-C. Hsu, T.-Y. Su, K.-Y. Lin, C.-M. Lin and T.H. Dai, J Hazard Mater 2007, 147, 1056-1062. https://doi.org/10.1016/j.jhazmat.2007.01.141

55. V. Gupta, A. Mittal and V. Gajbe, J. Colloid Interface Sci. 2005, 284, 89-98. https://doi.org/10.1016/j.jcis.2004.09.055

56. B. Nandi, A. Goswami and M. Purkait, Appl. Clay Sci. 2009, 42, 583-590. https://doi.org/10.1016/j.clay.2008.03.015

57. Y.-S. Ho and G. McKay, Process Biochem. (Amsterdam, Neth.) 1999, 34, 451-465.

58. I. Langmuir, J. Am. Chem. Soc. 1918, 40, 1361-1403. https://doi.org/10.1021/ja02242a004

59. U. Freundlich, Z. Phys. Chem. 1906, 57, 385-470.

60. F. Bessaha, K. Marouf-Khelifa, I. Batonneau-Gener and A. Khelifa, Desalin Water Treat 2016, 57, 14609-14621. https://doi.org/10.1080/19443994.2015.1063090

61. L. Tian, J. Zhang, H. Shi, N. Li and Q. Ping, J. Dispersion Sci. Technol. 2016, 37, 1059-1066. https://doi.org/10.1080/01932691.2015.1080610

62. B. A. Fil, Part. Sci. Technol. 2016, 34, 118-126. https://doi.org/10.1080/02726351.2015.1052122

63. M. Ghaedi, A. Ansari, M. H. Habibi and A. R. Asghari, J. Ind. Eng. Chem. 2014, 20, 17-28. https://doi.org/10.1016/j.jiec.2013.04.031

64. G. Kiani, M. Dostali, A. Rostami and A. R. Khataee, Appl. Clay Sci. 2011, 54, 34-39.

65. P. Saha, S. Chowdhury, S. Gupta and I. Kumar, Chem. Eng. J. (Lausanne) 2010, 165, 874-882. https://doi.org/10.1016/j.cej.2010.10.048

66. J. Chang, J. Ma, Q. Ma, D. Zhang, N. Qiao, M. Hu and H. Ma, Appl. Clay Sci. 2016, 119, Part 1, 132-140. https://doi.org/10.1016/j.clay.2015.06.038 
67. L. Cottet, C. Almeida, N. Naidek, M. Viante, M. Lopes and N. Debacher, Appl. Clay Sci. 2014, 95, 25-31. https://doi.org/10.1016/j.clay.2014.03.023
68. H. Fan, L. Zhou, X. Jiang, Q. Huang and W. Lang, Appl. Clay Sci. 2014, 95, 150-158.

https://doi.org/10.1016/j.clay.2014.04.001

\section{Povzetek}

Glavni namen raziskav je študij adsorpcije barvil malahitno zeleno in metilensko modro na dve vrsti naravne gline, obdelane s površinsko aktivnimi snovmi. Rezultati SEM, XRD, IR in termične analize potrjujejo vezavo organskega dela na glino. Rezultati kažejo najboljše ujemanje s kinetiko psevdo prvega reda na organo-glino za obe barvili. Ravnotežji za obe vrsti barvil lahko opišemo z Langmuirjevo izotermo za obe vrsti modificirane gline. Vrednosti parametrov Langmuirjeve in Freundlichove izoterme kažejo na ugodno adsorpcijo. Maksimalna adsorpcijska kapaciteta $\mathrm{q}_{\mathrm{m}}$ po Langmuirjevem modelu pri $25^{\circ} \mathrm{C}$ je $294-303 \mathrm{mg} / \mathrm{g}$ in se dobro ujema $\mathrm{z}$ eksperimentalnimi podatki. 